\title{
Collision Types of Motorcycle Accident and Countermeasures
}

\author{
Tien-Pen Hsu, Ku-Lin Wen \\ Institute of Civil Engineering, National Taiwan University \\ Roosevelt Road Sec. 4 No. 1 Taipei, Taiwan \\ hsutp@ntu.edu.tw; wengulin@ntu.edu.tw
}

\begin{abstract}
Taiwan has the highest motorcycle ownership of 608 motorcycles per 1000 people in the world. The motorcycle safety is always the hottest issue. This paper aimed at analysing the most frequently occurred collision types of motorcycle involved accidents according to the accident data collected at 80 selected highest accident prone intersections and then to create the new countermeasures accordingly. The most frequently occurred collision types are 1. Sideswiped collision due to change lane, 2. Right Angel collision during change interval, 3.Left turning other Angle collision by left turning movement raised by turning movement against straight movement, 4. Right turning other Angle collision by right turning movement raised by turning movement against through movement, and Rear-end collision related to change interval and width of intersection. The effective countermeasures proven include the right turn lane layout modification, the inter-green time recalculated according to the motorcycle speed, separate direction of movement between car and motorcycle, and to provide the segregate waiting zone the turning movement.
\end{abstract}

Keywords: Motorcycle, Accident, Collision Diagram, Safety Countermeasures, Traffic Engineering

\section{Introduction}

Taiwan has the highest motorcycle ownership of 608 motorcycles per 1000 people in the world. The figure 1 shows the highest 21 motorcycle ownership countries the world.

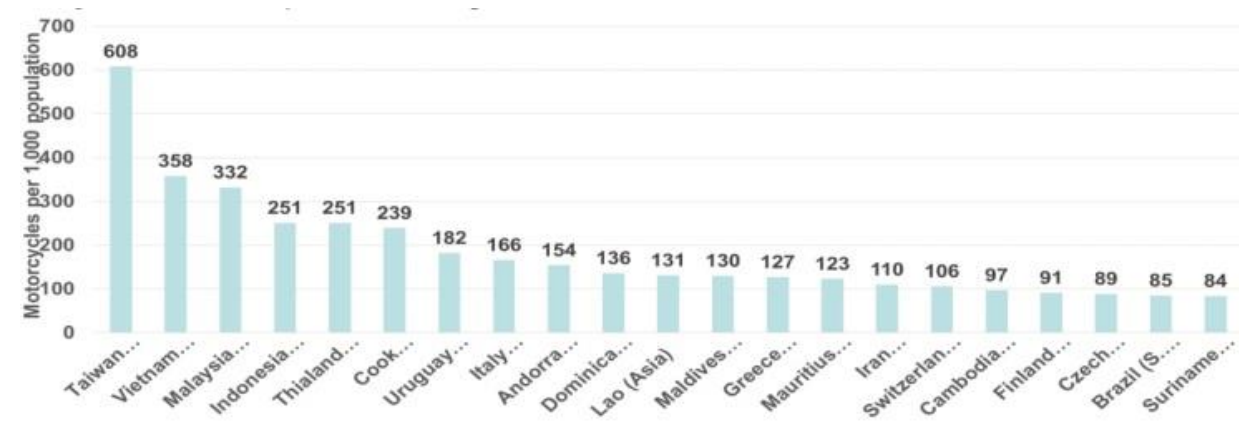

Fig. 1: The highest motorcycle ownership countries (no. of motorcycles per 1000 people) Sources: Data source: Global Status Report on Road Safety, WHO 2013 and Taiwan Statistic 2013.

In Taiwan, the traffic flow is a typical mixed traffic flow with high motorcycle traffic composition of $60 \%$ in urban area. Under this kind of traffic flow, the interaction between different types of vehicles and motorcycles become very complicated. Then, the motorcycle accidents is always the hottest issue regards traffic safety. Thanks of the segregated flow concept to separate the motorcycle from the other car traffic, in the past, in Taiwan, the fatality of the motorcyclist has reduced gradually and shows the lowest fatality rate in the high motorcycle ownership countries, as shown in the Fig. 2 by comparing with other countries. The death of motorcyclist per 100,000 motorcycle has 10.6 in Taiwan, which is the lowest in Asian Countries. The countermeasures based on the segregated flow concept consists of Motorcycle exclusive lane on urban street (on curb side), motorcycle prior lane on street with high curb activity( on curb side), motorcycle is not allowed to drive on inner lanes, head start holding zone at signalized intersections for motorcycle, two-stage left-turn regulation of motorcycle.(Hsu, 1996). 


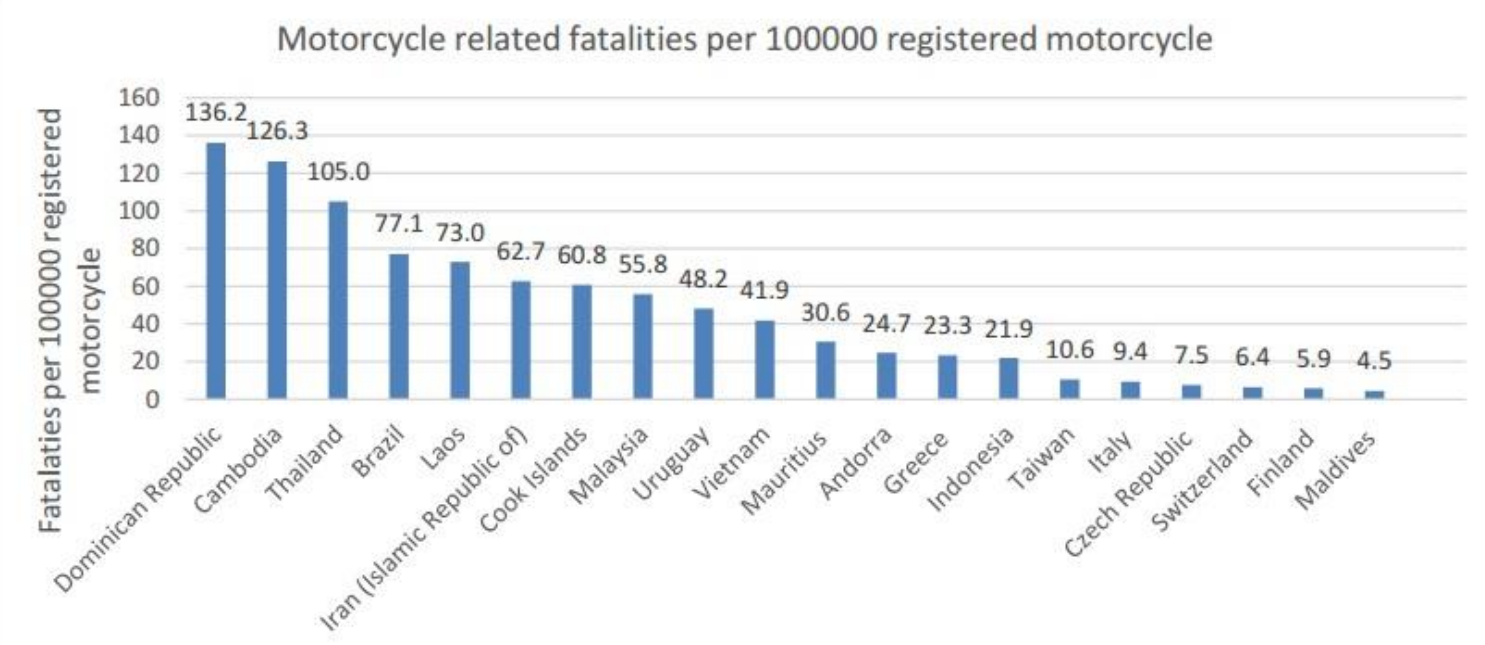

Fig. 2: Comparison of motorcyclist fatality in Asia (death per 10,000 motorcycle) Data source: Global Status Report on Road Safety, WHO 2013 and Taiwan Statistic 2013 (death within 30days).

\section{Most Frequently Occurred Collision Type of Motorcycle Accidents}

We collect the accident data from 80 accident prone intersections, and drawn the collision diagram, as illustrated in Fig. 3 which is an example of accident prone intersection. (Hsu, 2013, 2014, 2015)

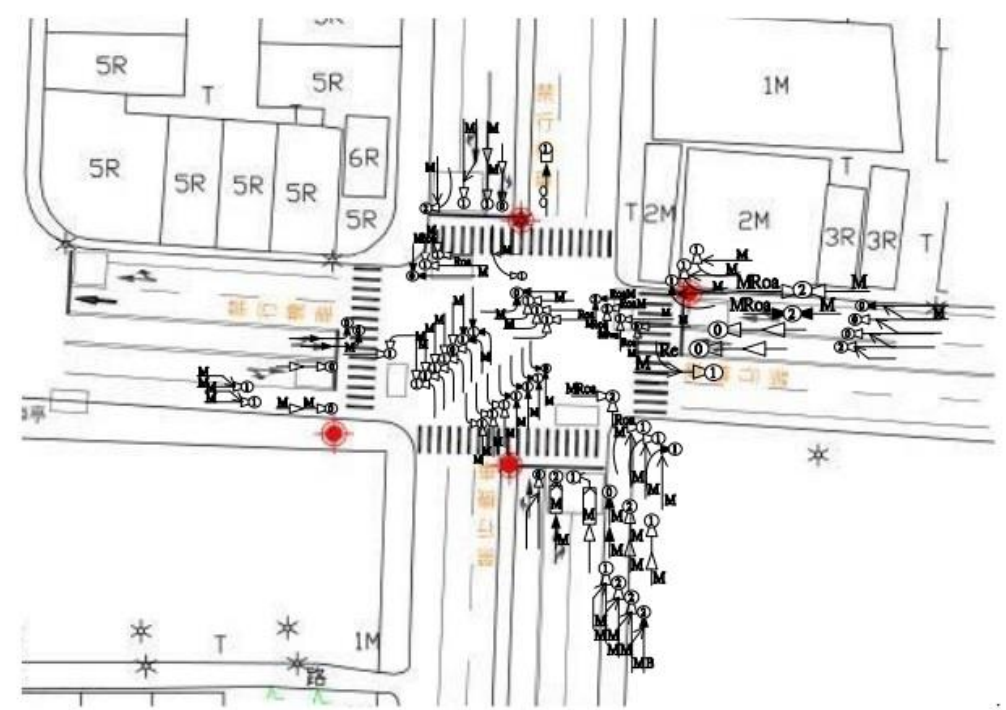

Fig. 3: Collision diagram of accidents at a signalized intersection.

Table 2: The percentage of collision type of motorcycle involves accidents.

\begin{tabular}{|c|c|}
\hline Motorcycle accident Collision type & Percentage \\
\hline Turn movement other angle collision(right turn and left turn) & $45.7 \%$ \\
\hline Sideswipe (same direction) & $8.2 \%$ \\
\hline Rear end collision & $4.8 \%$ \\
\hline Right angle collision & $22.2 \%$ \\
\hline Rollover or fall & $2.2 \%$ \\
\hline Sideswipe (opposite direction) & $2.2 \%$ \\
\hline Other & $14.3 \%$ \\
\hline
\end{tabular}


By counting the number of accident of collision type, the most frequent accidents are as following:

1. Sideswiped collision same direction by lane changing

2. Right Angel collision

3. Left turning other Angle collision by left turning movement

4. Right turning other Angle collision by right turning movement

5. Rear-end collision: change interval and width of intersection

\section{Cause and Remedial Countermeasures}

\subsection{Sideswiped by lane change with same direction}

Causes:

- Traffic movements of different directions will use the same lane under mixed traffic with motorcycle.

During lane changing to get right direction, the car and motorcycles will weave to cross to each other within a lane. Therefore, sideswiped collision occurred frequently on such a lane at intersection.

Countermeasures:

- Need to post a sign to provide advanced lane usage information for choosing the right lane in advance.

- The lane direction marking should be drawn clearly.

- If the width of mixed lane is sometimes too wide, then, the right turn vehicle will not make right turn on the right side of lane. In such case, it needs facility to guide straight vehicle to use the left side of the lane and right-turn vehicle to use right side of lane.

\subsection{Left turning other angle collision}

Causes:

- Lacking left-turn protected signal phase, left-turn vehicles makes left turn after ending of green time.

The motorcycles on opposite lane are still on departing the intersection. The collision between leftturn vehicle and opposite straight motorcycle often occurs under such situation. It can be improved by reducing central-divided-island, adding left-turn signal phase, or installing left-turn guiding line etc. Then, the conflicts between left-turn vehicle and opposite motorcycle.

Countermeasures:

- Lack of left turn guidance and waiting zone markings

- Lack of left turn protection signals

- Improper inter-green time between left turning and opposing vehicles

- Need for leading left turn in T-intersection

\subsection{Right turning other Angle collision by right turning movement}

Causes:

- Motorcycle exclusive lane, slow traffic lane, bus stop, road side parking in the right hand side of the right turn lane

- Lack of guiding signs and markings guided the right turning cars to keep right

- Motorcycles are used to keep right of the road.

Countermeasures:

- Cancel exclusive motorcycle lane from $60 \mathrm{~m}$ upstream of the stop line at intersection

- Make the curb lane as mixed lane for car and motorcycle. Then, right-turn vehicle can change to curb side lane before arriving intersection and turn right. The conflict between straight motorcycle and rightturn vehicle could be prevented.

\subsection{Rear-end collision}

Causes:

- Improper inter-green time

- Acute "skew" intersection angle restricts road user's sight angle

- Improper position of motorcycle "two way left turn" waiting zone, left turning motorcycle volume exceeding the waiting zone design volume or other reasons that affect buffer space for forthcoming and obstacle vehicles 


\section{Countermeasures}

- Make longer yellow and all-red time

- Add new signal head and adjust the stop line location to enhance the visibility

- Correct the waiting zone space and location to prevent the conflict.

\section{Case Study}

Using a signalized intersection as example, the collision diagram of the intersection is illustrated as Fig. 4. The intersection 66 accidents a year. The motorcycle was involved into 45 accidents of them. Most of them are the car against motorcycle accident, which are 30 accidents.

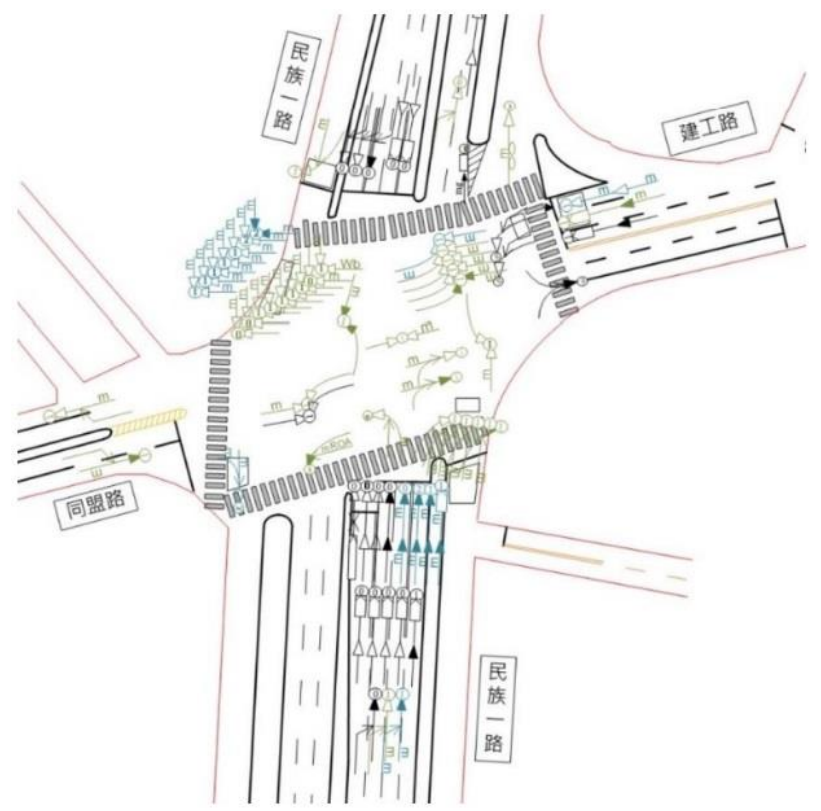

Fig. 4: Collision diagram of example intersection.

Table 2: Collision type by car and motorcycle occurred at intersection.

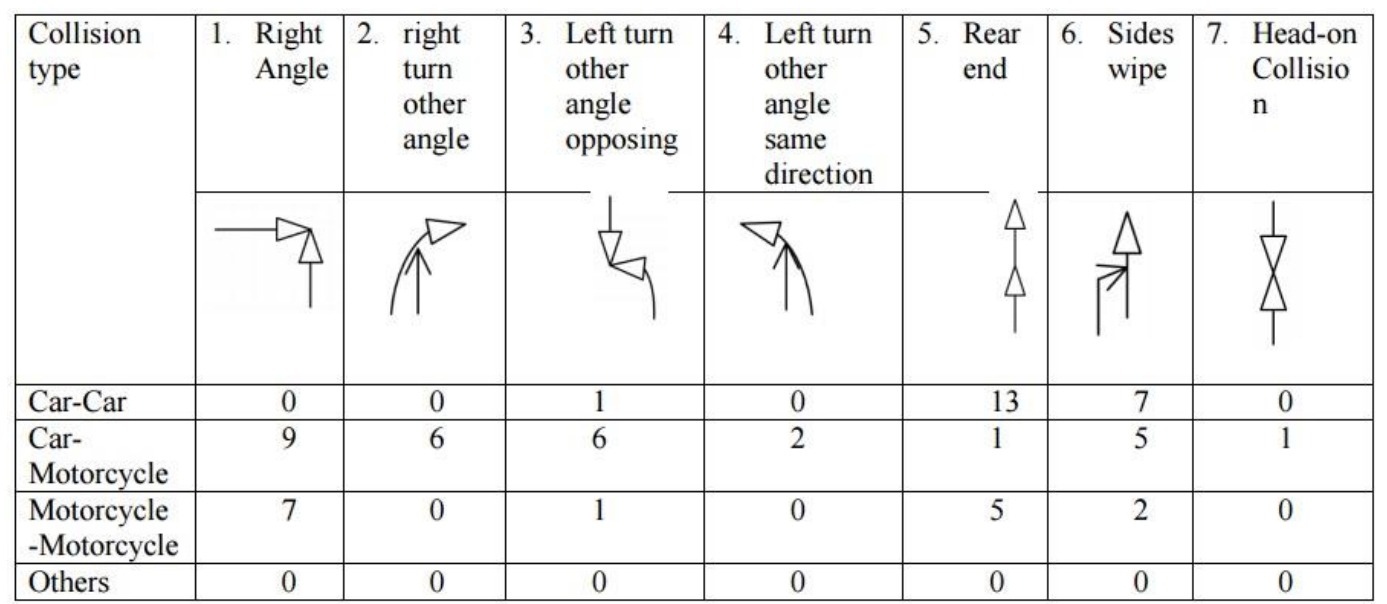

The possible remedial countermeasure for preventing the collision between the vehicles at this intersection are proposed as follows:

- Southbound: add the sign for signal usage, draw yellow net mark for preventing stopping on conflict area, extend the not lane change line marking for fast-slow divided island, post the advanced lane usage sign to direct the 
lane usage in advance, draw land direction arrow marking on curb lane to divide the turning movements, add $1 \mathrm{~s}$. more for yellow time, add lighting at this approach for preventing accident in night time.

- Eastbound: draw right turn arrow marking, replace the lane layout to be 3 lane approach, draw the lane usage direction arrow marking to prevent the illegal left turn from outside lane, add $2 \mathrm{~s}$. longer for all red time and $1 \mathrm{~s}$. longer for yellow time.

- Westbound: draw the edge line marking, draw the alignment for guiding turning movement, draw a central guiding line marking for inconsistent lane layout between far-side and nearside between eastbound and westbound, add $2 \mathrm{~s}$. longer for all red time due to the too wide intersection.

- Northbound: add $1 \mathrm{~s}$. longer for yellow time, set back of the waiting zone for two stage left-turn motorcycle.

Through implementing the accident remedial countermeasures, which all target specific collision type, the accident occurrence will be significantly reduced expectedly as shown in Table 4. Because all the countermeasures are directly related to the collision type regarding the traffic engineering facilities, therefore, the implement of the countermeasure will have exact performance prospectively. The countermeasures are related to remedy the $85 \%$ of accidents, which are 70 accidents. In the Table 4, A1 accident means fatal accident; A2 means injury accident; and A3 means only property damage accident.

Table 3: The expected reducing accident occurrence by remedial countermeasures.

\begin{tabular}{|r|r|r|r|r|r|r|r|r|r|}
\hline $\begin{array}{r}\text { No. } \\
\text { Accident }\end{array}$ & \multicolumn{4}{|l|}{ Existing accident occurrence } & \multicolumn{3}{|c|}{$\begin{array}{l}\text { Expected Accident occurrence } \\
\text { after improvement }\end{array}$} & \multicolumn{3}{|l|}{$\begin{array}{l}\text { Expected reduction of accident } \\
\text { occurrence }\end{array}$} \\
\hline $\begin{array}{c}\text { Type of } \\
\text { severity }\end{array}$ & A1 & A2 & A3 & A1 & A2 & A3 & A1 & A2 & A3 \\
\hline $\begin{array}{l}\text { Accident } \\
\text { No. }\end{array}$ & 0 & 46 & 24 & 0 & 5 & 5 & 0 & 41 & 19 \\
\hline
\end{tabular}

\section{Conclusion and Suggestion}

This paper investigated the collision types of motorcycle involved accidents and comparing with the car involved accidents. Accordingly, the remedial countermeasures are proposed to prevent the accident occurrence. Thanks to the relation between the collision and defect of existing traffic engineering, the remedial countermeasure for enhancing traffic safety will be easy to be identify. The proposed traffic safety engineering improvement countermeasures for enhancing the safety of motorcycle traffic have been implemented and have effected to enhance the motorcycle traffic safety. It can be taken as the practical design basis for road design for enhancing motorcycle traffic safety.

\section{References}

[1] T.-P. Hsu, “Analysis of Motorcycle Traffic Engineering Problems and Countermeasures," in Proceeding of Chinese Ind Motorcycle Traffic and Safety Conference, 1996.

[2] T.-P. Hsu, "A Study on Improvement Countermeasure Accident Prone Intersections in Kaohsiung City," Research Report, Department of Transportation, Kaohsiung City, 2013, 2014, 2015. 